on the stretch and steadied by the traction of the liga. ture. I separated the blades of the scissors and pushed them through the gut, then by closing the handles I made a good opening into the fore part of the bowel. I slipped my finger into the opening, and changing $\mathrm{my}$ scissors for button ended ones, I sripped through the tight edges, the ligature being gently pulled down during the whole time. By this means I opened two thirds of the closed bowel, and the posterior flap was brought through the sphincter. I passed a suture through it to the verge of the anus, and on withdrawing my finger a quantity of meconium was expelled by the straining efforts of the child. An India-rubber bottle full of warm water was injected and returned by the child's efforts, and soon afterwards the little patient fell asleep. I passed up a candle bougie twice daily for three or four days, and about the fifth day I took out the stitch from the bowel and snipped off the flap at a distance higher than the ligature, which I had left protruding through the anus. I do not know whether there would have been any risk of the bowel receding had it not been confined by the suture, but it gave no trouble after its removal. A warm water injection was given daily; the bowels acted well, and the child lived long enough to have the bowels brought into the normal condition. I should certainly adopt the same treatment in a similar state. The ligature answers several purposes; it draws down the pouch, it tightens the membrane so that the bowel does not recede before the scissors, and after the incision has been made, it makes tense the edges and permits the opening to be enlarged with ease and safety.

$I$ have related these cases in succession, as the abnor. mal condition was so much alike in both, but the follow. ing case occnrred about June 1856 , between the two cases cited. The parents were innkeepers, and after the child had been born a few hours, the attendant noticed that no stool passed, though the child made some straining efforts. On examination, it was found that the anus was closed. I waited over two days, and as there was no protrusion or resistance when the finger was pressed against the perinæum, I advised an exploratory incision. This I did with my lancet to the extent of half an inch, and passed my finger through the wound, hoping to come into contact with the globular distended bowel, but I failed to discover any fulness or anything indicating the presence of the lower bowel. I allowed the case to go on for a day or two longer, and I then advised Amussat's operation in the left loin to re. lieve the child's suffering. Either from absence of the descending colon, or from the incorrect performance of this operation, I did not succeed in finding the bowel, and I closed the wound without being able to give the child the relief I had hoped for. The parents would not allow a post mortem inspection, and I can only mention this as a case where the bowel was defective for some distance from the anus.

\section{RARE CASES IN MIDWIPERY.}

By Edward Copeman, M.D., Physician to the Norfolk and Norwich Hospital.

[Continued from page 664 of last volume.]

CaSE xxIr. Cerebral Affection after Labour. I was summoned in the middle of the night on September 16th, a distance of eigbteen miles, to Mrs - (who had been confined about ten days) in consequence of a severe attack of illness after labour, with a threatening of puerperal convulsions. She was of middle age, and the mother of several chidren, one, if not more, horn in China, where she had once suffered from cerebral disturbance, subdued at length by large doses of opium ; of which drug she was said to be at the time so tolerant that not less than five or six grains produced any effect. The night before I saw her, she had been suddenly seized with pain in the head, intolerance of light and noise, and confusion of mind, so that she scarcely knew where she was, and believed herself to be dying. She was very faint, and when her surgeon arrived, he ordered turpentine in drachm doses, several of which had been taken before 1 got there, and from which she expressed the greatest comfort, saying she felt at once that it would save her life. Before taking it, her pulse was 140. I found it a little under 100 : and hearing she had been unable to sleep for several nights, I advised a full opiate enema. The lochia had not stopped, neither were there any decided uterine symptoms; but I considered that her brain, naturally susceptible, had become irritable and exhausted from want of sleep.

The enema produced a very good effect, being followed by seven hours' sleep; and a few days afterwards I was in. formed that all was going on perfectly well.

Her hushand told me she made a very good recovery.

CASE xxIIr. Puerperal Disease. I was summoned to a distance, late on the evening of Saturday, October 4 th, to visit a delicate lady, about 35 years of age, and mother of a large family, coming in rapid succession. She had been confined ten or twelve days, and there was some difficulty with the placenta. There was no distinct history of a chill, but the nurse said the lochial discharge had been offensive for a day or two, and paler than it ought to have been, but this was only mentioned after putting the question to her. I found her very much depressed, with rapid pulse, confused sensorium, and great loss of power, hoth nervous and muscular; and yet there were no decided uterine or abdominal symptoms. However, we applied turpentine stupes to the abdomen as a precaution, washed out the vagina, gave a strong opiate enema to quiet the nervous system and procure sleep; and prescribed frequent small doses of quinine and chloric æther, with wine and good nourishment to support her strength.

I did not see the patient again, but have since been informed by her surgeon, that after a rather severe struggle, she ultimately recovered. She could not take the quinine, but continued the chloric æther, and turpentine stupes. After my visit, she exhibited more decided puerperal symptoms; her body becoming prominent, her inind more disturbed; she had no sleep but what was produced by medicine, and thirty or forty minim doses of chlorodyne answered the purpose well. The turpentine greatly reliever the tympanitic condition of the abdo. men; but after this had subsided, she was attacked with phlegmasia dolens. In spite of this complication, however, the result was favourable, and the patient is now downstairs and resuming her family duties.

CASE XXrv. Puerperal Disease: Fatal. Mrs.-, aged 28 years, a delicate lady and very deaf, had been confined ahout a fortnight, when I was called to see her on October 1st. The history given me was as follows. Before her confinement she had an attack of bronchitis, which much reduced her strength; her labour soon followed, and the placenta required artificial removal on account of hæmorrhage, which for the moment was severe, and made her very faint. She went on pretty well for a day or two, and then had an attack of pleuro-pneumonia of the left side, accompanied by very acute pain, and re. lieved by antimony, blistering, calomel and opium etc. When this gave way to treatment, she complained of slight abdominal pain, the abdomen was found to be tumid, and there was commencing phlegmasia dolens in the right leg. The secretion of milk had ceased, and the lochia had changed colour. These latter symptoms made their appearance two days before I saw her; and I found her in a very serious condition, suffering from most threatening puerperal mischief, which had been masked by the more acute disease in the chest, and for a day or two escaped observation. Her pulse was 140 or more, and her respiration hurried and whistling. The sensorium was not much disturbed, but on dozing she 
felt rather confused. The chest-affection was apparently cured. The abdomen was not tender, but very tympani. tic and conical; and I discovered uterine tenderness on deep pressure above the right groin. She had no sickness nor diarrhca. The lochia were muco-purulent and very offensive: and the nurse told me she had noticed the bad smell four or five days, but had not mentioned it. Muscular power was at a very low ebb, and her general condition most unfavourable. Turpentine was applied to the abdomen this morning, and we now gave her a drachm dose internally; we also enveloped the whole limb affected by phlegmasia dolens, the right leg, in moist flannel sprinkled with turpentine; an application which $I$ have found of much more service in that disease than any other treatment whatever. All other medicines were discontinued ; frequent vaginal washings ordered, and a turpentine enema the next morning, should there be no relief from the bowels; the turpentine to be also repeated internally twice in the night, and mild nourishment administered. I left her at 8 P.M., without a hope of recovery from such a frightful complication of illness, the only circumstances at all in her favour being that her manner was not very unfavourable, and her brain but little disturbed.

On the 2nd, her surgeon sent me the following report : "I have seen Mrs. - this morning. She has had a restless night, bowels very much relaxed, tympanitis not so much, mind quite intact, pulse not so quick. She expresses herself as unable to take any more turpentine, but we go on with the external application. I have given her a chalk mixture with a little opium, catechu, cascarilla, and chloric æther. It is a very bad case, yet there are some favourable symptoms. It is remarkable how during the chest-affection, this disease was masked; in fact, there appeared no symptoms of such until the other was removed."

On the 4th, I heard she was still alive, and in some respects better. The body was much less swelled; the diarrhœa was stopped; the leg not painful; but her pulse was still rapid and she was very weak.

On the 6th, I received a letter requesting another consultation, but stating that in many respects the patient had been going on favourably. On my arrival in the afternoon, I was told a serious change had taken place in the morning, and she was fast sinking. I found her quite sensible, without pain either in the abdomen or leg, and with scarcely any swelling in either. But she was so exhausted and feeble, and her pulse small and very rapid, with a corresponding frequency of respiration, that it was clear she must die. However, she lingered on without any other symptoms than extreme exhaustion until the 9th, and then quietly sank.

\section{[To be continued.]}

Death of a Surgeon from an Oferdose of Prussic AcID. The following particulars are from the Waterford Mail:- "We regret to bave to announce the sudden and premature death of Joseph Sawyers, Esq., surgeon of the 8ith Regiment, which occurred on Friday evening. Mr. Suwyers had been in the habit of taking small doses of prussic acid, and on Friday evening he felt unwell, and mentioned to his servant that he would not go to dinner; the servant laid a bottle containing prussic acid and one containing essence of peppermint on the table, and it is surmised that he took the prussic acid in mistake. A coroner's inquest was beld on Saturday, and a verdict was found that the death was caused by an overdose of prussic acid. 'The remains wese interred with militury honours, at the Abbey Church, this (Monday) morning, and were accompanied by all the officers-some having come from a considerable distance to pay this mark of respect to their deceased comrade, who was much beloved and is sin cerely regretted by them."

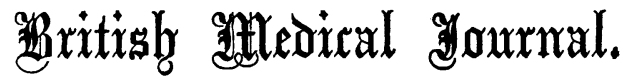

SATURDAY, JANUARY 10TH, 1863.

\section{SCIENCE AT HOME AND ABROAD.}

THe truth of the old adage, that no man is a prophet in his own country, is very strikingly exemplified by the manner in which we in this country are too apt to treat the contributions to science of foreigners, and the contributions of our own countrymen. We have more than once taken occasion to call attention to this act of unpatriotic partiality; and, in fact, have recommended those of our scientific workers, who wish their observations to be duly appreciated by their own countrymen, to have them transferred into a foreign dress, and brought out, in the first instance, in a foreign country, under a foreign name. We verily believe that the translation "from the German," for example, into English of such productions would ensure for them a far better chance of attentive and serious consideration than they would obtain if their British authors had produced them originally in their mother tongue and country.

Our remarks have called forth the following pertinent observations from the pen of one of our most accomplished scientific observers :-

"English observations are not epitomised in the same way as foreign, and the result is, that a most erroneous impression exists amongst practitioners, viz., that the scientific work performed in this country is exceedingly small, and bears no comparison, either in quantity or quality, with that produced on the continent. Sometimes papers seem to be selected for translation in consequence of the number of letters in their authors' names-sometimes, because the author boldly reiterates statements, the truth of which was disproved half a century ago. Thus, recently, we have had the subject of spontaneous generation re-opened, and the most unsatisfactory experiments of certain French observers reported at some length. If these gentlemen still remain uninfluenced by the multitude of facts which have for years been accumulating against their pet theory, it seems scarcely desirable to encumber English journals with their dogmatic assertions. There are, and probably there will always be, people who will maintain that living beings result from the accidental approximation of certain inanimate particles to each other, but it is surely unnecessary to give very wide publicity to such untenable vagaries.

"There is just now a fashion in this country of giving very undue prominence to the work of foreigners, while that of our own countrymen is underrated. Foreigners are themselves surprised at the sort of articles which are sometimes translated into English journals. 